\title{
Mapeamento de competências: ferramenta para a comunicação e a divulgação científica
}

\author{
Competence mapping: tool for scientific \\ communication and diffusion
}

Adriana Aparecida Lemos TORRES 1

Fabrício ZIVIANI²

Sandro Marcio da SILVA ${ }^{3}$

\section{Resumo}

Este artigo tem como objetivo analisar a viabilidade do modelo de mapeamento de competências a partir da implementação de um catálogo de especialistas ou guia de fontes para divulgação, compartilhamento de conhecimentos e ampliação da visibilidade da universidade. A pesquisa quantitativa de natureza descritiva foi desenvolvida na Diretoria de Divulgação e Comunicação Social da Universidade Federal de Minas Gerais. Para coleta de dados, foram utilizados questionários distribuídos para 71 servidores e contratados, com retorno de 60 respondentes. Os resultados apontam que o mapeamento de competências poderá ser uma ferramenta de comunicação ao servir para consulta do setor de comunicação institucional, bem como de seus diversos públicos, como a comunidade acadêmica, a imprensa e a sociedade. Pode ainda ser considerado como instrumento de divulgação científica, por facilitar o acesso aos pesquisadores, aqueles que constroem o conhecimento e, ao mesmo tempo, estão entre os responsáveis pela popularização da ciência. A partir da identificação e do apontamento dos seus especialistas e de suas competências, o mapeamento de competências permite também o compartilhamento do conhecimento, a disponibilização das experiências, o intercâmbio de saberes e a construção de redes de colaboração entre especialistas.

Palavras-chave: Comunicação social. Divulgação científica. Gestão do conhecimento. Mapeamento de competência.

\begin{abstract}
The aim of this article is to analyze the feasibility of the model of competence mapping by implementation of a catalogue or expert guide to sources for dissemination, knowledge sharing and increasing the visibility of the university. This research of a quantitative, descriptive nature, was developed by the Directorate of Advertising and Media Board of Universidade Federal de Minas Gerais. For data collection questionnaires were used, being distributed to 71 servers and workers, with 60 completed and returned. The results show that the mapping of skills can be a communication tool that serves to consult the corporate communication agency, and its various stakeholders such as academic community, media and society. It may also be considered a means of disseminating scientific topics, by facilitating access to researchers, those who construct knowledge and simultaneously contribute to the popularization of science. By identifying and pointing out the specialists and their skills, competence mapping also allows knowledge to be shared, experience to be made available, interchange of skills and building of a network of cooperation among experts.

Keywords: Communication. Scientific dissemination. Knowledge management. Mapping of competence.

1 Coordenadora, Universidade Federal de Minas Gerais, Diretoria de Divulgação e Comunicação Social, Núcleo de Divulgação Científica. Belo Horizonte, MG, Brasil.

2 Doutorando, Universidade Federal de Minas Gerais, Programa de Pós-Graduação em Ciência da Informação. Av. Antonio Carlos, 6627, Pampulha, 31270-010, Belo Horizonte, MG, Brasil. Correspondência para/Correspondence to: F. ZIVIANI. E-mail: <fazist@hotmail.com>.

3 Professor Doutor, Fundação João Pinheiro, Centro de Estudos de Políticas Públicas. Belo Horizonte, MG, Brasil.

Recebido em 11/11/2011, reapresentado em 23/5/2012 e aceito para publicação em 11/6/2012.
\end{abstract}




\section{Introdução}

A sociedade da informação e do conhecimento estabelece novas exigências que vêm alterando o processo de gestão nas organizações. Assim, o capital humano, as competências, as redes sociais, os processos de aprendizagem, dentre outros aspectos, passam a ser muito valorizados.

O conhecimento é o principal ativo das organizações, constituindo um fator de competitividade. Nesse cenário, todo o processo que permeia o conhecimento torna-se importante, desde sua produção até sua disseminação. Gerenciar o conhecimento que se possui é também imprescindível para as organizações. Nesse contexto, surgem novos modelos de gestão, destacando-se aqui a Gestão do Conhecimento, na qual o mapeamento de competência atua como uma importante ferramenta.

O mapeamento de competências é uma forma de identificar, sistematizar e evidenciar as competências da organização. A partir dele, é possível identificar os pontos fortes e as lacunas de conhecimentos da instituição, o que permite tomar decisões importantes, como investir na formação dos seus profissionais ou na contratação de pessoas para as áreas fracas ou inexistentes do conhecimento.

Essa pesquisa partiu da seguinte problematização: como o mapeamento de competências pode colaborar com a comunicação e a divulgação científica de uma instituição de ensino superior? Esta pesquisa tem como objetivo analisar a viabilidade do modelo de mapeamento de competências para uso na implementação de um catálogo de especialistas ou guia de fontes para divulgação, compartilhamento de conhecimentos e ampliação da visibilidade da universidade.

Ao ser implantado em uma instituição de ensino superior e ser disponibilizado em forma de catálogo ou guia, o mapeamento de competências poderá ser uma ferramenta de comunicação ao servir de consulta para o setor de comunicação institucional, bem como para os seus diversos públicos, como a comunidade acadêmica, a imprensa e a sociedade como um todo. Ainda pode ser considerado instrumento de divulgação científica por facilitar o acesso aos pesquisadores, aqueles que constroem o conhecimento e, ao mesmo tempo, constituem um dos responsáveis pela popularização da ciência. Pode também ser um instrumento de captação de recursos para pesquisas, ao disponibilizar informações acerca dos especialistas e suas respectivas áreas de pesquisa e trabalho para empresas de fomento à pesquisa e ao ensino.

A partir da identificação e do apontamento dos seus especialistas e de suas competências, o mapeamento de competências permite também o compartilhamento do conhecimento, a disponibilização das experiências, o intercâmbio de saberes e a construção de uma rede de colaboração entre os próprios especialistas da instituição.

Assim, o presente trabalho inicia-se com um resgate teórico sobre os seguintes temas: Gestão do Conhecimento, mapeamento de competências, breve descrição da Universidade Federal de Minas Gerais (UFMG), divulgação científica e comunicação universitária.

Após o estudo bibliográfico, observaram-se a realidade e as demandas da Diretoria de Divulgação e Comunicação Social (DDCS) da UFMG a partir da aplicação de um questionário aos profissionais desse setor. Esses dados são apresentados em sessão específica deste artigo, após a exposição da metodologia utilizada, e justificam a proposta deste estudo, que é a confecção de um guia de especialistas da UFMG.

\section{Gestão do conhecimento}

Em todas as épocas, o conhecimento sempre foi alicerce para o desempenho superior de indivíduos, sociedades e países. Atualmente ele é foco das organizações, que buscam sobrevivência e competitividade no cenário econômico, por afetar profundamente as empresas e o trabalho dos indivíduos. Pode-se dizer que o conhecimento assumiu um papel dominante na economia mundial e tornou-se um recurso econômico relevante e o principal ativo das organizações.

Nesse contexto, surge uma nova economia, cuja fonte fundamental de riqueza são o conhecimento, a informação e a comunicação, e não os recursos naturais ou o trabalho físico (Stewart, 2002).

Davenport e Prusak (1998) afirmam que a vantagem produzida pelo conhecimento é sustentável por gerar retornos crescentes e dianteiras continuadas. Os ativos do conhecimento - ao contrário dos ativos materiais, que diminuem à medida que são usados, aumentam 
com o uso: o conhecimento compartilhado enriquece quem o recebe e, ao mesmo tempo, permanece com quem o doa. Dessa forma, conhecimento gera conhecimento.

Diante desse cenário, é imprescindível para as organizações a obtenção do conhecimento. Mas isso não basta. É preciso ainda que tenham consciência acerca do conhecimento que possuem, a fim de obterem o máximo proveito das informações e progredirem na produção contínua do conhecimento.

McGee e Prusak (1995) defendem que a informação, mais do que a terra ou o capital, será a força motriz na criação de riquezas e prosperidade. Como o sucesso é determinado pelo que se sabe, tem-se a importância das organizações saberem gerir e criar novos conhecimentos. Assim, a capacidade de produzir, gerenciar e disseminar o conhecimento torna-se fundamental para que a organização estabeleça vantagem competitiva em relação às demais e sobreviva no mercado. O compartilhamento de informações e conhecimento passa, então, a ser uma questão estratégica para as organizações obterem vantagem diante das demais, além de ser um grande desafio.

Tanto as empresas privadas quanto as públicas têm tomado consciência da importância de revisar seus modelos de gestão. As empresas privadas são motivadas pela necessidade de sobrevivência e competitividade no mercado, e as públicas pelo cumprimento de sua missão e pela qualidade de seus serviços. Nesse contexto atual de mudanças na gestão das organizações, a Gestão do Conhecimento tem sido amplamente discutida e apontada como forma de manutenção dos ativos intelectuais da estrutura organizacional.

Segundo Alves (2006, online):

A gestão do conhecimento é o mecanismo mediante o qual as organizações acumulam riqueza a partir do conhecimento de seus colaboradores e seu objetivo é tornar disponíveis grandes volumes de informação corporativa, compartilhando as melhores práticas e tecnologias, além de permitir a identificação e o mapeamento dos ativos de conhecimento e informações, o que os torna utilizáveis e úteis e os transforma em informação essencial ao desenvolvimento pessoal e coletivo.
Para Hernades et al. (2000), a Gestão do Conhecimento é um processo pelo qual uma organização consciente e sistematicamente coleta, cria, organiza, compartilha e quantifica seu acervo de conhecimentos para atingir seus objetivos estratégicos.

O objetivo da Gestão do Conhecimento nas organizações, segundo Davenport e Prusak (1998), é fazer com que o conhecimento existente ou inovador torne-se disponível a todos os membros da organização. A Gestão do Conhecimento se ocupa, portanto, dos processos gerenciais e da infraestrutura física e digital, que facilitam, favorecem e estimulam os processos humanos de criação, compartilhamento e uso de conhecimentos individuais e coletivos (Terra, 2005).

Uma melhor compreensão sobre o que vem a ser Gestão do Conhecimento e sobre o conhecimento em si só é possível após o entendimento e a diferenciação de termos que se relacionam, mas não são sinônimos. Em muitas organizações, o conhecimento tem sido considerado e tratado como sinônimo de dado e informação.

Os conceitos de dado, informação e conhecimento devem ser analisados de forma hierárquica. Dados se transformam em informações e essas em conhecimento. Para Davenport e Prusak (1998), os dados são um conjunto de fatos distintos e objetivos, relativos a eventos. Não têm significado inerente; descrevem apenas parte daquilo que aconteceu. Nada dizem sobre a própria importância, irrelevância ou significância. Os dados tornam-se informação quando dotados de relevância e propósito.

Stewart (2002) diz que informações são dados contextualizados. Para Davenport e Prusak (1998), a informação é como uma mensagem, geralmente na forma de documento ou de uma comunicação audível, que tem por finalidade exercer um impacto sobre o destinatário, mudando sua forma de ver algo, seu julgamento e comportamento. De acordo com Nonaka e Takeuchi (1997), a informação, quando concebida, proporciona um novo ponto de vista para a interpretação de eventos ou objetos, o que torna visíveis significados antes invisíveis ou lança luz sobre conexões inesperadas. A informação afeta o conhecimento quando lhe acrescenta algo ou o reestrutura. Desse modo, torna-se meio ou material para extrair e construir o conhecimento.

O conhecimento, de acordo com Davenport e Prusak (1998), é uma mistura fluida de experiência conden-
193 
sada, de valores, com informação contextual, a qual proporciona uma estrutura para a avaliação e a incorporação de novas experiências e informações. Para Nonaka e Takeuchi (1997), o conhecimento é identificado com a crença produzida (ou sustentada) pela informação. Ao contrário da informação, o conhecimento diz respeito a crenças e a compromissos e está relacionado à ação. $E$, assim como a informação, conhecimento diz respeito a significado; é específico ao contexto e situação relacional.

De acordo com Polanyi (1983), o conhecimento pode ser classificado em dois formatos que se relacionam: conhecimento explícito (teórico) e conhecimento tácito (prático). Segundo Polanyi (1983), o formato tácito é pessoal, prático, específico ao contexto, e isso o torna difícil de ser formulado e comunicado. Já o conhecimento explícito ou "codificado" é teórico; refere-se ao conhecimento transmissível em linguagem formal e sistemática.

O formato tácito refere-se a um conhecimento subjetivo; trata-se de habilidades inerentes a uma pessoa ou sistema de ideias, percepção e experiência, sendo difícil de ser formalizado, transferido, comunicado ou explicado a outra pessoa. Já o formato explícito é relativamente fácil de codificar, transferir e reutilizar; pode ser formalizado em textos, gráficos, figuras, desenhos, esquemas, diagramas etc., facilmente organizado em base de dados em publicações em geral, tanto em papel como em formatos eletrônicos (Nonaka;Takeuchi, 1997).

O conhecimento humano é, portanto, o somatório do conhecimento tácito (capacidade, habilidade e experiência) e do explícito (conhecimento formal). A interação desse conhecimento na organização, por meio do processo de aprendizagem, constitui o conhecimento coletivo, organizacional, que é o que gera o diferencial competitivo almejado pelas empresas. Como já mencionado, o conhecimento é tido como ativo intelectual e agrega valor à organização. Esses ativos intelectuais somados às decisões e estratégias da empresa criam o "capital intelectual" da organização.

Uma forma de constatar a existência do conhecimento organizacional e uma tentativa de quantificar o valor desse capital intelectual é observar a diferença entre o valor de mercado de uma empresa de capital aberto e o seu valor contábil líquido oficial. Essa diferença corresponde aos seus ativos intangíveis (Sveiby, 1998).
Stewart (2002) afirma que esses ativos intangiveis são compostos por três grupos: a competência dos funcionários (talentos e capacidade de agir em diversas situações); a estrutura interna (a organização, com seus conceitos, patentes, modelos e sistemas administrativos e de computadores) e as estruturas externas (imagem da organização e relação com os clientes e fornecedores).

Como esses ativos intangíveis são necessários e o conhecimento constitui fator estratégico às organizações, a função da organização na Gestão do Conhecimento é fornecer contexto apropriado, ou seja, condições e ambiente favoráveis para a criação do conhecimento.

O conhecimento resulta de uma combinação de tipos de conhecimentos explícitos (acessíveis, codificados, registrados) e tácitos (pessoais, não codificados). E no ambiente organizacional se desenvolve em espiral partindo do indivíduo, sendo compartilhado em grupos e se incorporando a organizações (Costa; Kruchen, 2008, p.4).

A interação do conhecimento tácito e do explícito na organização é que proporciona a manifestação da criatividade e, consequentemente, as mudanças, transformações e inovações.

Os conhecimentos tácito e explícito não são entidades totalmente separadas, mas se completam mutuamente, interagem um com o outro e realizam trocas nas atividades criativas dos seres humanos (Nonaka; Takeuchi, 1997).

Ainda para Nonaka e Takeuchi (1997), o modelo dinâmico da criação do conhecimento está ancorado no pressuposto crítico de que o conhecimento humano é criado e expandido por meio da interação entre o conhecimento tácito e o conhecimento explícito, mediante quatro processos de conversão do conhecimento: socialização, externalização, combinação e internalização. Essa conversão é um processo social entre indivíduos, e não confinada dentro de um indivíduo.

Esses quatro modos constituem o motor do processo de criação do conhecimento como um todo e são os mecanismos pelos quais o conhecimento individual é articulado e amplificado na organização. Portanto, a criação do conhecimento organizacional é um processo em espiral, que começa no nível individual e vai subindo, ampliando comunidades de interação que cruzam fronteiras entre seções, departamentos, divisões e organizações (Nonaka;Takeuchi, 1997). 
Para que o conhecimento explícito se torne tácito, Nonaka e Takeuchi (1997) afirmam que são necessárias a verbalização e a diagramação do conhecimento sob a forma de documentos, manuais ou histórias orais. A documentação ajuda os indivíduos a internalizarem suas experiências, aumentando assim seu conhecimento tácito. Documentos e manuais facilitam a transferência do conhecimento explícito para outras pessoas, ajudando-as a vivenciar indiretamente as experiências dos outros.

O conteúdo do conhecimento criado por cada modo de conversão do conhecimento é naturalmente diferente: a socialização gera o que pode ser chamado de "conhecimento compartilhado"; a externalização gera "conhecimento conceitual"; a combinação dá origem ao "conhecimento sistêmico", como a geração de protótipos e tecnologias de novos componentes; a internalização produz "conhecimento operacional" sobre gerenciamento de projeto, processo de produção, uso de novos produtos e implementação de políticas (Nonaka;Takeuchi, 1997).

Conforme Nonaka e Takeuchi (1997), os ciclos de conversão do conhecimento, passando várias vezes por esses quatro modos, formam uma espiral que serve para analisar e entender os mais diversos casos de criação e disseminação do conhecimento. No processo de criação do conhecimento, a partir das conversões, são criados quatro tipos de conteúdos, que interagem entre si na espiral do conhecimento: conhecimento compartilhado, conceitual, operacional e sistêmico.

De acordo com Carleton (2011), dentre as formas de motivar e reter os trabalhadores quanto ao conhecimento, pode-se destacar a capacidade de proporcionar- Ihes um trabalho desafiador e significativo, que permita o desenvolvimento de aprendizagem e de carreira, além de reconhecer as contribuições que eles proporcionam.

Empresas que desejam ser competitivas devem estimular a criação do conhecimento gerando ambientes, criando situações e ocasiões para que os quatro modos de conversão do conhecimento possam acontecer. Afonso e Calado (2011) relatam que a criação de valor no atual ambiente organizacional pressupõe que o objetivo organizacional não seja tão somente a produção e perpetuação de um bem, mas também a perpetuação do conhecimento gerado.
O conhecimento de uma organização pode ser representado por formas gráficas. Costa e Kruchen (2008) defendem que a construção de representações gráficas do conhecimento gerado nas organizações pode contribuir de maneira eficaz para o desenvolvimento, compartilhamento e distribuição do conhecimento nas organizações. Os mapas podem contribuir para a melhoria dos processos internos da organização, bem como para a visualização de estratégias e o alinhamento de suas competências essenciais.

É imprescindível aqui a definição de gráfico e de mapas. Segundo acepção de Costa e Kruchen, (2008, p.3):

Gráfico pode ser definido, de forma genérica, como uma "representação da linguagem por sinais visuais". Nesse sentido, a palavra "gráfico" incorpora vários tipos de representações visuais de informações, entre os quais: diagramas, fluxogramas, histogramas e mapas. Mapas, portanto, são um tipo gráfico. Geralmente, apresentam um conjunto de elementos ou qualidades, associados de acordo com um modelo ou uma regra, e fornecem direção ou orientação. Dessa forma, os mapas permitem a visualização de um conceito, uma ideia (como os mapas mentais, mapas conceituais, mapas semânticos, mapas do conhecimento e mapas cognitivos, por exemplo) ou possibilitam a localização física ou geográfica (como o mapa-múndi, os mapas rodoviários e os mapas do ativo do conhecimento de uma organização, entre outros).

Quando se fala em mapeamento, Costa e Kruchen (2008, p.4) estão se referindo à "ação de identificar dados, informações e conhecimentos, tornando-os acessíveis por meio da elaboração de mapas". A linguagem de gráficos e suas construções - como esquemas, organogramas, mapas etc. -, desempenham a função didática de fazer visíveis as coisas que, por natureza, não o são. Constitui um instrumento facilitador de aprendizagem e para a Gestão do Conhecimento.

Quanto aos mapas do conhecimento, existe uma variedade de representações, como topografias, mapas de ativos do conhecimento, mapas de fontes de conhecimento, matrizes de conhecimento. Como são registros vivos e dinâmicos, devem estar em constante atualização.

Num ambiente empresarial, os mapas podem atuar como subsídio para a melhoria dos processos 
relacionados com a competitividade, como a tomada de decisões estratégicas, e, sobretudo, no desenvolvimento de uma visão compartilhada de suas competências e de suas metas. Além disso, pode servir como guia e agenda para suas ações.

O mapeamento do conhecimento é parte fundamental nos processos essenciais de Gestão do Conhecimento: "os mapas do conhecimento podem ser utilizados tanto para localizar especializações quanto para mapear os ativos do conhecimento, permitindo que quaisquer tipos de conhecimentos possam ser formalizados e tornados acessíveis" (Costa; Kruchen, 2008, p.3).

Costa e Kruchen (2008, p.89) reforçam que esses tipos de representações "aumentam a transparência e auxiliam a identificação de especialista ou de fontes do conhecimento, permitindo, assim, que o usuário classifique o conhecimento novo em relação ao existente e ligue tarefas com especialistas ou ativos do conhecimento". Ainda defendem que as principais funções dos mapas no ambiente empresarial são: comunicar rapidamente um conteúdo, auxiliando e complementando a comunicação verbal; auxiliar a visualização de sistemas complexos; atuar como base comum para discussão, apresentando informações de modo claro e direto; compartilhar vocabulários; possibilitar e facilitar a recuperação de conteúdos; e suportar o desenvolvimento de conhecimentos estratégicos e seu registro. Em suma, o mapa funciona como um material de base para a difusão do conhecimento.

Brandão e Bahry (2005) afirmam que o setor público também tem procurado adotar a gestão por competências como alternativa de gestão flexível e empreendedora, que possibilite melhorar a qualidade e a eficiência dos serviços públicos. Sob essa perspectiva, os métodos e as técnicas de mapeamento de competências constituem elemento central na gestão por competências.

Contudo, o mapeamento de competências extrapola seu objetivo primário - ferramenta para a gestão por competências -, sendo proposto neste trabalho como ferramenta para a comunicação e a gestão da informação. Nesse sentido, é proposta a utilização da primeira etapa do processo de mapeamento, que é a identificação das competências necessárias à organização e à identificação das competências existentes.

\section{Mapeamento de competências}

Para Dutra (2008), o conceito de competências foi estruturado pela primeira vez em 1973 pelo americano David McClelland, que buscava uma abordagem mais efetiva que os testes de inteligência nos processos de escolha de pessoas para as organizações. Contudo, essa definição de competências passou por constantes atualizações e ainda é uma tarefa em execução por parte da academia.

Sob a ótica americana, competência era vista como um input, ou seja, como qualidades requeridas para o exercício do cargo, relacionadas ao conjunto de conhecimentos, habilidades e atitudes. Atualmente, esse conjunto, embora ainda importante, apresenta-se insuficiente, devido ao contexto de incertezas e mudanças em que as organizações estão inseridas. Dutra (2008, p.28) afirma que"esse enfoque é pouco instrumental, uma vez que o fato de as pessoas possuírem um conjunto de conhecimentos, habilidades e atitudes não é garantia de que elas irão agregar valor à organização".

Em seguida, surgiu outra definição de competência, decorrente da visão de autores europeus. O foco está no contexto, sendo a competência vista como um output, com efetiva legitimação do valor da entrega realizada pelo indivíduo (Dutra, 2008). Assim, ocorreu o deslocamento do foco que estava sobre o estoque de conhecimento e habilidades para a forma como a pessoa mobilizava seu estoque e repertório de conhecimentos e habilidades em determinado contexto, de modo a agregar valor para o meio no qual se inseria.

Foi durante os anos 1980 e 1990 que muitos autores passaram a definir competência associando-a às suas realizações e àquilo que elas proveem, produzem ou entregam.

A noção do quem vem a ser uma entrega é apresentada por Dutra (2008) e pode ser entendida como a reconhecida contribuição de um indivíduo ou de um grupo no cumprimento de certa competência, em que o valor agregado ao negócio é diretamente proporcional à complexidade da entrega. Fica explícito, então, que a noção de competência só é concretizada com uma ação. Ruas (2005, p.44) propõe o conceito de competência como "uma ação através da qual se mobilizam conhecimentos, habilidades e atitudes pessoais e profissionais, a fim de 
cumprir certa tarefa ou responsabilidade, numa determinada situação".

Atualmente, conforme Dutra (2008), os autores que definem competências procuram pensar a competência como o somatório dessas duas linhas, ou seja, como a entrega e as características da pessoa que podem ajudá-la a entregar com maior facilidade.

Na visão de Takahashi e Fischer (2009), competência está relacionada à capacidade de combinar e mobilizar adequadamente recursos (de forma apropriada ao evento) e não apenas à manutenção de uma vasta gama de conhecimentos e habilidades. Essa ação gera uma nova configuração de competências resultante do aprendizado ao lidar com a nova situação. Dutra (2008) afirma que competência pode ser atribuída a diferentes atores, como organização e pessoas.

As competências organizacionais são definidas por Ruas (2005) como aquelas que resultam do relacionamento e da cooperação de recursos e capacidades coletivas da organização, bem como interações de seus grupos e áreas de atuação, e que têm papel decisivo no desempenho estratégico das organizações. Dutra (2008) defende que esse conjunto de competências da organização é que estabelece suas vantagens competitivas no contexto em que se insere.

A competência de pessoas, por sua vez, é definida como o"saber agir responsável e reconhecido, que implica mobilizar, integrar, transferir conhecimentos, recursos, habilidades, que agreguem valor econômico à organização e valor social ao indivíduo" (Fleury; Fleury, 2007, p.30).

Há uma relação íntima entre competências organizacionais e individuais, uma vez que é mútua a influência de umas e de outras. Ao colocar organização e pessoas lado a lado, segundo Dutra (2008), verifica-se um processo contínuo e enriquecedor de troca de competências, no qual a organização transfere seu patrimônio para as pessoas, enriquecendo-as e tornando-as mais preparadas para enfrentar novas situações. As pessoas, por sua vez, transferem seu aprendizado e conhecimento à organização, capacitando-a a enfrentar novos desafios.

Competência e estratégia são interligadas. Ao relacioná-las, Fleury e Fleury (2007, p.190) propõem o conceito de círculo vicioso, afirmando que:
[...] segundo essa abordagem, a organização, situada num ambiente institucional, define a sua estratégia e as competências necessárias para implementá-la, num processo de aprendizagem permanente. Não existe uma ordem de precedência nesse processo, mas antes um círculo vicioso, em que uma alimenta a outra mediante o processo de aprendizagem.

A estratégia da organização constitui uma ferramenta gerencial muito necessária. Contudo, o sucesso do planejamento estratégico não está condicionado apenas às qualidades do plano, mas principalmente à competência decisória dos que vão implementá-lo. Fleury e Fleury (2007) defendem ainda que as competências da organização são identificadas na relação dinâmica da mobilização dos recursos e da realização das entregas.

Para que se consiga o alinhamento da estratégia com as competências da organização, primeiramente se faz necessário identificá-las e, por vezes, moldá-las de acordo com as necessidades específicas.

Dutra (2008) afirma que a gestão por competências auxilia a organização no processo de conhecimento de seus recursos humanos e de suas competências. Afinal, é importante conhecer o que se tem e o que se sabe.

A Gestão do Conhecimento, segundo Brandão e Bahry (2005), propõe-se a orientar esforços para planejar, captar, desenvolver e avaliar, nos diferentes níveis da organização - individual, grupal e organizacional -, as competências necessárias à consecução de seus objetivos. Uma vez formulada a estratégia da organização, torna-se possível realizar o mapeamento de competências.

Behr (2010) relata que, no mapeamento de competências, devem ser avaliadas as competências existentes em uma empresa e as competências fundamentais para seu desenvolvimento. O mapeamento de competências permite, além de outras coisas, alocar adequadamente os colaboradores na empresa, identificar potencialidades e carências de competências e, ainda, selecionar e desenvolver competências necessárias ao desempenho estratégico da organização.

Behr (2010) ainda menciona que o mapeamento de competências passa por um processo que visa a identificar as competências e a avaliá-las, formular conclusões e registrar resultados. O objetivo da fase de identificação 
de competências é elaborar uma lista de competências relevantes no setor em que a empresa atua. Entre as técnicas utilizadas para a realização do mapeamento de competências podem ser destacadas: análise documental, entrevista, grupo focal e questionário. Na fase de avaliação, o objetivo é avaliar se a empresa encontra-se em vantagem ou desvantagem competitiva quanto a cada uma das competências. Na etapa de formulação de conclusões e registro de resultados, o objetivo é interpretar os dados, identificar as áreas críticas e tirar conclusões. As áreas críticas são destacadas para que sejam analisadas mais profundamente. Após esse processo, é possível ter uma visão sobre a força das competências existentes na organização.

\section{A UFMG e a divulgação científica}

Fundada em 1927, a Universidade Federal de Minas Gerais é uma instituição de grande repercussão e reconhecimento, tanto em âmbito nacional quanto internacional. Em 2010, 21 programas de pós-graduação da UFMG, distribuídos em diferentes áreas do conhecimento, tiveram reconhecimento de padrão de qualidade internacional pela Coordenação de Aperfeiçoamento de Pessoal de Nível Superior (Capes), órgão ligado ao Ministério da Educação (MEC). Segundo a avaliação, a instituição mineira abriga $71 \%$ dos programas de mestrado e doutorado com padrão de qualidade internacional do estado. Dos 31 com notas máximas (6 e 7), 22 estão na UFMG. No mesmo ano de 2010, a UFMG foi apontada como líder no ranking de transferência de patentes no País. Percebe-se, assim, a contribuição da universidade no fomento à economia a partir da transferência de conhecimento do âmbito acadêmico para o setor produtivo e para a sociedade.

Em sua estrutura atual, a UFMG conta com 2652 professores ativos, 4378 funcionários técnico-administrativos, 52660 alunos (de graduação, especialização, residência médica, mestrado, doutorado, educação básica e profissionalizante e outros). No âmbito do ensino, oferece 321 cursos: 75 de graduação, 81 de especialização, 38 de residência médica, 67 de mestrado e 60 de doutorado, dentre outros (ex.: cursos à distância). No âmbito da pesquisa, conta com 799 grupos de pesquisa, 12859 publicações científicas indexadas, 343 patentes nacionais e
111 patentes internacionais. No âmbito da extensão, a universidade conta com 70 programas, 375 projetos, 397 cursos, além de promoção de eventos e prestações de serviços diversos.

A universidade é, por excelência, um espaço de produção de conhecimento científico sobre os mais variados temas. A importância dessa produção científica não se restringe ao âmbito acadêmico, pois o conhecimento científico é cada vez mais necessário à sociedade. Para o cidadão comum, constitui um recurso ao qual se recorre para auxílio e para orientação nas decisões cotidianas. É, portanto, um instrumento para a compreensão da natureza e da vida social. Sendo assim, a divulgação científica é de extrema relevância para a sociedade.

A divulgação científica, que pode ser considerada genericamente como uma atividade de circulação de conhecimento dirigida para fora de seu contexto original, isto é, para fora de uma comunidade de limites restritos, que produz e faz circular em seu interior conhecimento científico específico (Martins, 2006, p.9).

Através dos trabalhos de divulgação científica, a UFMG tende a aumentar sua contribuição e sua projeção na sociedade e a reforçar o seu papel social enquanto formadora não apenas de profissionais de qualidade, mas de cidadãos mais conscientes e críticos e, portanto, mais preparados para atuar nos processos de tomada de decisões. A UFMG, nesse sentido, desenvolve uma ampla política de comunicação voltada não apenas aos alunos, professores e servidores, mas também a toda comunidade externa. Na divulgação dos seus programas de atuação, pesquisas desenvolvidas, conhecimentos produzidos e eventos realizados, são utilizados os veículos de comunicação tradicionais como TV, rádios, jornais, portais da Internet, cartazes e outras publicações gráficas, além dos veículos próprios da UFMG.

A comunicação institucional tem como principal papel a divulgação da universidade e do seu principal "negócio", que é a produção e a disseminação do conhecimento. Dessa forma, pode-se considerar a divulgação científica como um dos principais papéis da comunicação institucional. Para realizar a comunicação institucional, a universidade conta com a Diretoria de Divulgação e Comunicação Social (DDCS), conhecida como Centro de Comunicação (Cedecom), responsável pelos produtos e serviços de comunicação da UFMG. Esse órgão de apoio 
à reitoria é dividido em núcleos ou setores, a saber: Rádio UFMG Educativa, TV UFMG, Núcleo Web, Agência de Notícias (jornalismo impresso e do site), Núcleo de Planejamento e Criação Gráfica, Núcleo de Comunicação Interna, Núcleo de Divulgação Científica, Administrativo e Assessoria de Imprensa. Além dessa diretoria, a UFMG conta com assessores de comunicação em algumas unidades acadêmicas.

A Diretoria de Divulgação e Comunicação Social da UFMG atua como um gestor das informações e da comunicação da universidade dirigida aos diversos públicos com os quais se relaciona. Nesse público, estão inclusos a comunidade interna (alunos, funcionários, professores e pesquisadores), a imprensa, empresas de fomento, empresas privadas (em busca de consultoria), órgãos públicos e sociedade em geral.

Diariamente, a Diretoria de Divulgação e Comunicação Social presta atendimentos a esse público, inclusive à imprensa, e se relaciona com ele. O setor de assessoria de imprensa atua como mediador entre a UFMG e a mídia externa: sugere pautas sobre as ações da universidade; atende demandas dos veículos de comunicação, viabilizando o contato dos jornalistas com o corpo de especialistas da instituição; planeja e realiza assessoria para a divulgação de eventos e pesquisas; acompanha a publicação de matérias sobre a universidade nos diversos veículos de comunicação, dentre outras atribuições. Essa atuação da assessoria auxilia a UFMG em sua missão de oferecer à população o conhecimento produzido, além de ampliar a visibilidade da universidade como instituição pública, bem comum de toda a população.

Outro instrumento de comunicação da universidade que merece destaque é o site, desenvolvido para cumprir o importante papel de dar visibilidade às informações da instituição, bem como de acesso aos serviços disponíveis, aos projetos desenvolvidos e aos conhecimentos produzidos.

\section{Métodos}

Esta pesquisa foi realizada na Diretoria de Divulgação e Comunicação Social (DDCS) da Universidade Federal de Minas Gerais (UFMG), conhecida como Centro de Comunicação (Cedecom), situada no campus Pam- pulha. A DDCS é composta por 118 profissionais: 71 servidores e contratados e 47 bolsistas.

O objetivo desta pesquisa é analisar a viabilidade do modelo de mapeamento de competências para uso na implementação de um catálogo de especialistas ou guia de fontes para divulgação, compartilhamento de conhecimentos e ampliação da visibilidade da universidade.

Vergara (2003) apresenta uma tipologia que classifica as pesquisas quanto aos fins e quanto aos meios. Quanto aos fins, a pesquisa poder ser: exploratória, descritiva, explicativa, metodológica, aplicada e intervencionista.

Esta pesquisa, quanto aos fins, é descritiva; de acordo com Braga (2007), a pesquisa descritiva tem como objetivo identificar as características de determinado problema ou questão e descrever o comportamento dos fatos e fenômenos. Os métodos mais utilizados para levantamentos de dados são o questionário e a entrevista; para análise, é comum o uso de softwares estatísticos.

No caso deste estudo, a utilização dessa técnica contribuiu para identificar e explicar os atuais problemas relacionados ao processo de comunicação da universidade, principalmente no que diz respeito à organização e à disponibilização de informações. Já a pesquisa aplicada, segundo Vergara (2003), tem como principal objetivo gerar conhecimentos para aplicação prática dirigidos à solução de problemas específicos. Procurou-se, então, levantar a percepção dos funcionários e gestores da DDCS em relação ao atendimento e à prestação de informações no setor. Quanto aos meios, foram realizadas uma pesquisa bibliográfica com base em material já elaborado - constituído principalmente de livros e artigos da Internet -, e a aplicação, aos funcionários, com a devida autorização da diretoria, de um questionário do Cedecom, que foi um importante instrumento de pesquisa.

No que se refere à análise e à interpretação de dados, foi utilizada a abordagem quantitativa, que tem como objetivo gerar medidas precisas e confiáveis que permitam uma análise estatística. Para Martins eTheóphilo (2009), a pesquisa quantitativa é aquela em que os dados e as evidências coletadas podem ser quantificados, mensurados. Os dados são filtrados, organizados e tabulados, enfim, preparados para serem submetidos às técnicas e/ou aos testes estatísticos. Os dados são colhidos através 
de questionários com perguntas claras e objetivas, e os relatórios podem apresentar tabelas de percentuais e gráficos.

A amostra da pesquisa foi realizada da seguinte forma: foram aplicados 71 questionários, respondidos por 60 pessoas. O grupo de entrevistados é composto apenas pelos funcionários (servidores e contratados), não tendo participado os bolsistas. A restrição aos funcionários deve-se ao fato de eles terem uma visão melhor dos processos de comunicação, dentre eles o atendimento ao público. A grande rotatividade de bolsistas poderia comprometer os dados coletados, uma vez que nem todos permanecem tempo suficiente para conhecerem de perto a realidade do setor referente aos aspectos estudados.

\section{Mapeamento de competências: uma proposta para a UFMG}

Sendo a universidade um espaço de produção e transferência do conhecimento, e sendo crescente essa produção, a partilha do conhecimento torna-se um grande desafio, a fim de permitir seu usufruto. $O$ conhecimento científico e tecnológico deve, o quanto for possível, ultrapassar o âmbito da universidade e ser acessível a toda a sociedade.

A UFMG é uma importante fonte de informações científicas e tecnológicas em Minas Gerais. Seus pesquisadores e professores, por meio de suas pesquisas e atuação nas diferentes áreas do conhecimento, são frequentemente demandados para prestação de serviços e consultorias a órgãos públicos e empresas privadas.

Na pesquisa realizada junto aos profissionais da DDCS-UFMG, ao serem interrogados sobre a contribuição do conhecimento produzido na UFMG para com a sociedade, todos os respondentes (100\%) defenderam que esse conhecimento contribui para o desenvolvimento da sociedade, assim como para a comunidade acadêmica. Destaca-se a afirmação de um dos profissionais: "de forma geral, o desenvolvimento e a expansão dos conhecimentos podem nos levar a uma qualidade melhor de vida". Essa unanimidade nas respostas a esse questionamento vem ao encontro dos estudos bibliográficos que apontam a popularização do conhecimento como um dever das instituições de ensino superior e como uma benesse. Segundo
Oliveira (2001), a importância da divulgação científica se dá devido ao fato de que os avanços científicos são relevantes para vida humana e cada vez mais determinantes para os contextos social, econômico e político.

Muitos benefícios que o conhecimento produzido na UFMG proporciona à sociedade, à comunidade acadêmica e aos alunos foram apontados pelos entrevistados. Dentre eles, destacaram-se: o aumento do nível de educação e cultura do País; o desenvolvimento econômico, social e tecnológico do País; as novas tecnologias e conhecimentos que melhoram a qualidade de vida das pessoas e da sociedade; a solução para problemas do cotidiano, nas mais diferentes áreas; o aperfeiçoamento da democracia; o entendimento de aspectos da vida humana como a cultura e a arte; a prestação de serviços, produtos e informações de qualidade; o desenvolvimento de programas de extensão; a formação qualificada de recursos humanos em todas as áreas do conhecimento; e o desenvolvimento de especialistas que podem subsidiar políticas públicas, ações governamentais e outras entidades.

A UFMG é referência na produção do conhecimento: essa afirmação foi confirmada pela totalidade dos entrevistados. Dentre os fatores que justificam tal afirmação, destacam-se: o bom posicionamento no ranking nacional e internacional (ex.: na Capes e no CNPq); a notoriedade no cenário brasileiro; a excelência do corpo docente; a formação e a qualificação dos seus pesquisadores; a qualidade das pesquisas e o seu grande volume; o elevado número de patentes; o volumoso número de publicações; a repercussão que o conhecimento gerado na universidade produz nas instituições privadas e públicas; a presença constante e elevada de fomentos à pesquisa; a presença frequente da UFMG na mídia; e a boa credibilidade da instituição. Essa diversidade de justificativas demonstra que esse grupo de profissionais de comunicação da UFMG conhece e acompanha as notícias relacionadas à instituição onde atuam.

Ao serem questionados sobre a qualificação dos especialistas da UFMG, aqui entendidos como professores e pesquisadores, os entrevistados, em sua totalidade (100\%), afirmam que a grande maioria deles é qualificada. Logo em seguida, o questionário aborda o tema "fontes da universidade", ou seja, aborda quem pode falar em 
nome dela perante a sociedade, a mídia e as empresas de consultoria. A maioria, 75\% dos entrevistados, afirma que os especialistas da UFMG são considerados fontes e, portanto, podem responder por ela e em nome dela. Contudo, quando falam para a mídia e a sociedade, nem todos utilizam linguagem acessível a pessoas não especializadas no assunto tratado.

A imprensa é um dos setores que mais busca pesquisadores e professores para informar, debater ou esclarecer temas em questão na cena pública. Como especialistas em determinado assunto, os pesquisadores e professores da UFMG podem colaborar com a sociedade, colocando o conhecimento produzido em seu trabalho à disposição dela.

Relatórios de trabalho da assessoria de imprensa da DDCS apontam números significativos. No ano de 2009, foram contabilizados 3321 atendimentos à imprensa, com uma média diária de 13 atendimentos e o envio de 411 releases no ano. Já no ano de 2010, foi realizado um total de 4198 atendimentos à imprensa, com uma média de 16,85 atendimentos diários e com o envio de um total de 1347 releases. Percebe-se o aumento significativo do atendimento à imprensa de um ano para outro.

Quando interrogados sobre a busca por informações e contatos dos especialistas na DDCS, a imprensa foi apontada como quem mais solicita (78,3\%), seguida pelos órgãos administrativos e acadêmicos da universidade (23,3\%), empresas de consultorias (23,3\%), alunos da UFMG (20,0\%), sociedade em geral (15,0\%), outros órgãos públicos (11,6\%) e outros (5,0\%).

Sobre a frequência com que ocorrem essas buscas de informações e contatos dos especialistas da UFMG na DDCS, a opção "diariamente" foi a mais mencionada, observando-se a seguinte ordem: diariamente $(51,6 \%)$, semanalmente (18,3\%), quinzenalmente e mensalmente $(5,0 \%)$. Esses dados apontam para o fato de que as buscas por informações são muito frequentes.

A pesquisa mostra também que, apesar de a universidade ser uma fonte de conhecimento e, por consequência, de consultoria para empresas, sociedade e mídia, não há, no momento, uma organização dos dados básicos (quem são e o que fazem) sobre os especialistas da UFMG, nem mesmo na DDCS, responsável pela comunicação institucional. Um número considerável dos entrevistados
(27\%) respondeu que não existe um banco de dados sistematizado e atualizado, e (33\%) não souberam responder. Esse grande desconhecimento sobre o assunto representa o não uso desse banco de dados, o que aponta para sua inexistência ou sua pequena expressão.

Destaca-se que já existiu uma iniciativa nesse sentido. Tratava-se de um guia de especialistas da universidade, mas a iniciativa fracassou quando estava em processo de implementação. Atualmente, só existe uma tímida e incipiente organização de um banco de dados com os contatos dos especialistas, feita pela assessoria de comunicação. Ressalta-se que esse banco de dados não abarca a totalidade de especialistas, e muitos contatos estão desatualizados. Junte-se a isso o fato de que o acesso dos demais setores da DDCS a esse banco de dados, assim como da mídia e dos demais públicos, só ocorre com a mediação de um assessor, durante o horário comercial. Isso dificulta, em grande medida, a busca de informações por outros setores, como a TV UFMG e a Rádio UFMG Educativa. Sendo assim, o acesso e a recuperação dessas informações referentes aos especialistas da universidade não são eficazes.

A partir dessa realidade, ao serem interrogados sobre a necessidade de haver a confecção e a disponibilização de um guia de especialistas da UFMG e os seus possíveis benefícios, 88,3\% dos entrevistados afirmaram acreditar que essa ferramenta, se implantada, poderá solucionar problemas frequentes de comunicação, de recuperação da informação e de rapidez no fluxo de informações.

Os principais benefícios de um guia de especialistas, segundo os profissionais da DDCS, seriam: a facilidade de acesso às informações; a maior rapidez nas consultas; o acesso sem intermediação da assessoria de imprensa, ficando esta restrita a dados sigilosos (como contatos de telefones pessoais); a constante atualização dos contatos e o aumento da confiabilidade das informações; a melhoria no atendimento ao público; a possibilidade de formas diferentes de busca (na versão online); a melhoria da imagem da instituição, ao ser vista como organizada e transparente; a democracia no acesso ao conhecimento, por se ter acesso às suas fontes; o aumento da visibilidade dos especialistas; a facilidade para se identificar as fontes de acordo com a temática; o aumento do número de especialistas na mídia; a otimização do tempo dos pro- 
fissionais de comunicação da UFMG; e o maior conhecimento da própria universidade sobre si mesma.

Após a realização da pesquisa bibliográfica, da observação das novas práticas de gestão e da análise dos dados coletados no questionário aplicado, este artigo propõe o mapeamento de competências, a fim de se implementar um guia de especialistas da UFMG.

O mapeamento de competências, além de permitir a identificação e o mapeamento dos ativos de conhecimento e informações, permite que esses ativos sejam mais utilizáveis e úteis à universidade e à sociedade. Destacam-se como as principais funções dos mapas: a comunicação rápida, a possibilidade e a facilidade de recuperação de conteúdos e o fato de ser um material de base para a difusão do conhecimento.

O mapeamento proposto tem como foco a identificação de dados, informações e conhecimentos dos especialistas da UFMG, que serão disponibilizados em forma de catálogo ou guia, que pode contribuir de maneira eficaz para o desenvolvimento, o compartilhamento e a distribuição do conhecimento na universidade. Pode ainda contribuir significativamente para a melhoria dos processos internos da organização, dentre os quais se destaca o acesso às informações pela equipe de comunicação institucional a fim de disponibilizá-las quando solicitadas.

Esse trabalho de mapeamento permitirá o levantamento de várias informações. A partir disso, será preciso uma boa gestão da informação, a fim de que sejam bem utilizadas as informações levantadas. O guia de especialistas será uma ferramenta para a entrega de informação certa às pessoas certas no tempo certo. A importância dessas informações acerca dos especialistas pode ser mensurada pelo valor de seu uso, ou seja, por sua relevância no dia a dia. Ao dispor de um guia de especialistas e especialidades, a universidade poderá desempenhar melhor sua missão de produzir e disseminar o conhecimento, apontando para onde este se encontra.

A criação de um catálogo de especialistas tem como objetivos: proporcionar uma maior interação entre a UFMG, fonte do conhecimento, e a sociedade; facilitar o acesso da imprensa, de empresas privadas, de órgãos públicos e da sociedade em geral aos especialistas; atualizar e ampliar os meios de relacionamento, comunicação e informação na UFMG; contribuir para a divulgação do conhecimento científico produzido pela UFMG, tornando-o visível à sociedade a partir do mapeamento e do apontamento de suas competências; criar indicadores (como a UFMG está e como poderia estar em matéria de competências); e projetar melhor a UFMG no âmbito nacional e internacional.

A necessidade de um guia de especialistas vem ao encontro de várias demandas apontadas pelos funcionários: necessidade de instrumentos para sistematizar e disponibilizar as competências da UFMG, de compartilhamento do conhecimento, de disponibilização das experiências, de criação de rede de colaboração entre os pares (especialistas), de intercâmbios, dentre outros.

Esse guia, contudo, não traz o conhecimento em si, mas aponta onde ele está, apresentando a força das competências existentes na universidade. De certa forma, é uma maneira de disseminar a produção científica e tecnológica da instituição. Na pesquisa bibliográfica, os mapas do conhecimento podem ser utilizados para localizar e identificar especialistas ou fontes do conhecimento, funcionando como um material de base para a difusão do conhecimento.

O presente artigo propõe uma extrapolação do objetivo primário do mapeamento de competência - ferramenta para a gestão por competências -, ao sugerir seu uso como ferramenta para a comunicação, a divulgação científica e a visibilidade da UFMG. Nesse sentido, é proposta a utilização da primeira etapa do processo de mapeamento de competências, que é a identificação das competências necessárias à organização e das competências existentes, e a consequente produção de um guia de especialistas.

No guia de especialistas ou catálogo de fontes, deverão constar dados sobre os especialistas e os professores, a fim de ele ser uma ferramenta de comunicação tanto para os trabalhos desenvolvidos na DDCS, quanto para os demais públicos que demandam informações, como a comunidade acadêmica, a imprensa, os órgãos governamentais, as instituições privadas e a sociedade em geral. Esse guia será constituído por um banco de dados com informações básicas, mas imprescindíveis, sobre os especialistas, como: nome, formação e nível (mestrado, doutorado, especialidade), unidade acadêmica, 
departamento, telefone e endereço eletrônico institucionais e também uma lista dos temas nos quais são qualificados para emitir opiniões, prestar esclarecimentos ou divulgar informações. O catálogo contará ainda com informações gerais sobre a UFMG: dirigentes, endereço, telefone, fax e e-mail das unidades acadêmicas, de pró-reitorias e do gabinete da reitoria. Os dados disponíveis em base eletrônica poderão ser acessados por uma ferramenta de busca que permitirá ao usuário uma consulta por nome do especialista e por temas do conhecimento.

Esse catálogo poderá ser, então, uma importante forma de democratização do conhecimento produzido na UFMG, atendendo às necessidades da imprensa (difusão científica e acesso a opiniões especializadas sobre determinados assuntos), promovendo um intercâmbio entre os especialistas da UFMG - ao permitir uma visão compartilhada de suas competências-, e entre estes e os de outras universidades e instituições, e sendo útil para pesquisadores e empresas que queiram estabelecer outro tipo de relação com a universidade, como a prestação de serviços, consultorias ou o desenvolvimento de processos e de produtos. Com esse catálogo, a UFMG terá a oportunidade de se conhecer melhor, mapeando toda sua competência científica, além de proporcionar maior visibilidade aos trabalhos realizados na universidade, o que permitirá outras formas de acesso a esses trabalhos, parcerias e colaboração por parte da sociedade em geral.

De acordo com Afonso e Calado (2011), nas organizações que têm o conhecimento como recurso, o objetivo passa a ser a sustentabilidade do resultado gerado pela interação dos ativos tangíveis e intangíveis organizacionais. Isso ocasiona impacto enorme na organização, tanto em termos de estrutura física, quanto em termos de planejamento estratégico. Isso implica dizer que provavelmente missões organizacionais serão cada vez mais gerais e cada vez mais holísticas, buscando a integração de todo o conhecimento produzido no dia a dia organizacional.

\section{Considerações Finais}

O objetivo proposto neste estudo foi analisar o modelo de mapeamento de competências e propor a utilização desse processo a fim de se identificarem os especialistas (pesquisadores e professores) - apontando suas competências e áreas de atuação -, e de se criar um catálogo de especialistas ou guia de fontes para divulgação e compartilhamento de conhecimentos na UFMG. Assim, propõe-se uma extrapolação do objetivo primário do mapeamento de competência - ferramenta para a gestão por competências -, ao se sugerir seu uso como ferramenta para a comunicação, a divulgação científica e a visibilidade da UFMG. Nesse sentido, será utilizada a primeira etapa do processo de mapeamento de competências, que é a identificação das competências necessárias à organização e das existentes e a consequente produção de um guia de especialistas.

Após a realização de pesquisa bibliográfica sobre o tema e de pesquisa quantitativa junto aos profissionais da Diretoria de Divulgação e Comunicação Social (DDCS) da UFMG, o artigo aponta a necessidade da criação desse guia de especialistas e seus possíveis benefícios para a comunicação institucional, para a divulgação científica e seus públicos.

O mapeamento de competências será para a universidade uma ferramenta de comunicação, ao ser base para a construção de um guia de especialistas, o qual será um instrumento de divulgação da ciência ao facilitar o acesso aos especialistas - fonte do conhecimento -, além de ser captação de recursos para pesquisas, ao dar visibilidade às linhas de pesquisa e áreas de atuação dos pesquisadores. A partir da identificação e do apontamento de seus especialistas e suas competências, o mapeamento de competências permite também o compartilhamento do conhecimento, a disponibilização das experiências, o intercâmbio de saberes e a construção de uma rede de colaboração entre os próprios especialistas da instituição, ao apontar onde esse conhecimento se encontra e quem o produz.

Normalmente, a necessidade de informações e de conhecimentos especializados parte da sociedade. Cabe à universidade responder a essas demandas satisfatoriamente. Sabe-se que o Currículo Lattes, disponibilizado pelo Conselho Nacional de Desenvolvimento Científico e Tecnológico (CNPq), é uma fonte para identificar esse conhecimento. Nesse caso, não se leva em consideração a plataforma Lattes como consulta, pois existem algumas dificuldades com a utilização da ferramenta: a linguagem é pouco acessível e a atualização dos dados pelos pesquisadores não ocorre com fren- 
quência (normalmente no final dos projetos/pesquisa). O modelo proposto diferencia-se dessa plataforma porque procura desenvolver um conhecimento dinâmico e inovador.

Esse trabalho permitirá o apontamento do conhecimento da universidade: onde ele está e quem o disponibiliza. Contudo, não constitui a disponibilização do conhecimento em si, pois tem interface com outros processos que o disponibilizam, como os repositórios institucionais. Enquanto o catálogo de especialistas aponta onde está o conhecimento, o repositório possibilitará à comunidade acadêmica e à sociedade o acesso a ele a partir das publicações e dos produtos midiáticos nele arquivados e disponibilizados.

Os repositórios institucionais são definidos como coleções digitais de armazenamento, de preservação e de divulgação do conhecimento e possibilitam às universidades uma nova estratégia para o aumento da visibilidade e do valor público da instituição, ao demonstrar a relevância científica, social e econômica de suas atividades de pesquisa e de ensino. Possibilitam ainda a reforma da comunicação científica, ao alargar o acesso aos resul- tados das pesquisas. Destaca-se que o repositório institucional constitui uma importante ferramenta de apoio na Gestão do Conhecimento.

Após a realização da proposta deste artigo - realização do mapeamento de competências (identificação dos especialistas) e criação de um catálogo de especialistas-, a universidade poderá mapear as competências (identificação dos especialistas) e criar um catálogo de especialistas, permitindo maior visibilidade e compartilhamento da produção científica.

Assim, uma forma de continuidade do presente trabalho é a realização de um estudo sistematizado sobre repositório institucional e sua implantação a fim de se disponibilizar o conhecimento em si, a partir do acesso a publicações variadas, como teses, dissertações, monografias, artigos científicos, imagens e fotografias, aulas, palestras e cursos em vídeo, programas de TV e rádio, dentre outros. Essa biblioteca virtual (repositório) constituirá uma rica fonte do conhecimento: além de disseminar o conhecimento já existente, permitirá a geração de outros novos.

\section{Referências}

AFONSO, C.W.; CALADO, L.R. Organizações intensivas do conhecimento e sua relação com as estratégias de marketing. Revista de Administração, v.46, n.2, p.150-160, 2011.

ALVES, F.A. Gestão do conhecimento: uma ferramenta de apoio ao controle externo. Revista Controle, 2006. Disponível em: <http://www.tce.ce.gov.br>. Acesso em: 7 dez. 2010.

BRAGA, K.S. Aspectos relevantes para seleção de metodologia adequada à pesquisa social em ciência da informação. In: MUELLER, S.P.M. Métodos para pesquisa em ciência da informação. Brasília: Thesaurus, 2007. p.17-38.

BRANDÃO, H.P.B.; BAHRY, C.P. Gestão por competências: métodos e técnicas para mapeamento por competências. Revista do Serviço Público, v.56, n.2, p.179-192, 2005. Disponível em: <http://ieprev.com.br/UserFiles/File/RSP56_2.pdf\#page =57>. Acesso em: 7 dez. 2010 .

BEHR, A. Mapeamento de competências na pequena empresa de software: o caso da ABC Ltda. 2010. Dissertação (Mestrado em Administração) - Universidade Federal do Rio Grande do Sul, Rio Grande do Sul, 2010. Disponível em: <http://www. lume.ufrgs.br/handle/10183/22742>. Acesso em: 7 dez. 2010.

CARLETON, K. How to motivate and retain knowledge workers in organizations: a review of the literature. International Journal of Management, v.28, n.2, p.459-468, 2011.
COSTA, M.D.; KRUCHEN, L. O uso de mapas para gerenciar o conhecimento estratégico nas organizações. In: ANGELONI, M.T.(Org.). Gestão do conhecimento no Brasil: casos, experiências e práticas de empresas privadas. Rio de Janeiro: Qualitymark, 2008. p.3-20.

DAVENPORT, T.H.; PRUSAK, L. Conhecimento empresarial:como as organizações gerenciam o seu capital intelectual. Rio de Janeiro: Campus, 1998.

DUTRA, J.S. Competências: conceitos e instrumentos para a gestão de pessoas na empresa moderna. São Paulo: Atlas, 2008.

FLEURY, A.; FLEURY, M.T.L. Estratégias empresariais e formação de competências: um quebra-cabeça caleidoscópico da indústria brasileira. 3.ed. São Paulo: Atlas, 2007.

HERNADES, C.A.M.; CRUZ, C.S.; FALCÃO, S.D. Combinando o balanced scorecard com a gestão do conhecimento. Caderno de Pesquisas em Administração, v.1, n.12, p.1-9, 2000.

MARTINS, M.F. Divulgação científica e a heterogeneidade discursiva: análise de uma breve história do tempo de Stephen Hawking. Linguagem em (Dis)curso, v.6, n.2, p.231-240, 2006.

MARTINS, G.A.; THEÓPHILO, C.R. Metodologia da investigação científica para ciências sociais aplicadas. 2.ed. São Paulo: Atlas, 2009. 
McGEE, T.; PRUSAK, L. Gerenciamento estratégico da informação. Rio de Janeiro: Campus, 1995.

NONAKA, I.;AKEUCHI, H.Criação de conhecimento na empresa. 7.ed. Rio de Janeiro: Campus, 1997.

OLIVEIRA, F. Comunicação pública e cultura científica. Parcerias Estratégicas, n.13, p.201-208, 2001.

POLANYI, M. The tacit dimension. Gloucester: Peter Smith, 1983.

RUAS, R. Gestão por competências: uma contribuição à estratégia das organizações. In: RUAS, R.L.; ANTONELLO, C.S.; BOFF, L.H. (Org.). Os novos horizontes da gestão: aprendizagem organizacional e competências. Porto Alegre: Bookman, 2005. p.34-55.
STEWART, T.A. Capital intelectual: a nova vantagem competitiva das empresas. Rio de Janeiro: Campus, 2002.

SVEIBY, K.E. A nova riqueza das organizações: gerenciando e avaliando patrimônios do conhecimento. Rio de Janeiro: Campus, 1998.

TAKAHASHI, A.R.W.; FISCHER, A.L. Aprendizagem e competências organizacionais em instituições de educação tecnológica: estudos de caso. Revista de Administração, v.44, n.4, p.327-341, 2009.

TERRA, J.C.C. Gestão do conhecimento: o grande desafio empresarial. 5.ed. Rio de Janeiro: Elsivier, 2005.

VERGARA, S.C. Projetos erelatórios de pesquisaem administração. 4.ed. São Paulo: Atlas, 2003.
205

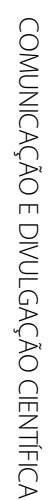


